\title{
LETTERS
}

\section{Anticardiolipin antibodies in patients with post-streptococcal reactive arthritis}

\author{
N Tamura, S Kobayashi, H Hashimoto
}

Ann Rheum Dis 2002;61:374

G roup A Streptococcus is a common bacterium that induces tonsillitis, pharyngitis, and pyoderma, and, furthermore, its metabolic products cause scarlatina. It is suggested that the molecular mimicry and cross reactivity between human tissues and the micro-organism are associated with immunogenic pathogenesis of well known poststreptococcal manifestations: acute rheumatic fever and acute glomerulonephritis. ${ }^{2}$ Recently, non-purulent arthritis after or during streptococcal infection, HLA-B27 unrelated "poststreptococcal reactive arthritis (PSReA)", has been reported as another manifestation associated with streptococcal infection..$^{3-5}$ The pathogenesis of PSReA is unknown, but it is likely that it is an immunogenic disorder similar to acute rheumatic fever.

Anticardiolipin antibodies (aCL) are often detected in patients with autoimmune diseases, especially systemic lupus erythematosus, and they can induce antiphospholipid syndrome. The presence of aCL has also been reported in streptococcal infection - that is, acute rheumatic fever and infectious endocarditis (IE). ${ }^{6}$

Here, in 13 patients with PSReA, we determined serum titres of aCL and $\beta_{2}$ glycoprotein I ( $\beta_{2}$ GPI) dependent aCL, which is a more crucial antigenic target than cardiolipin itself, ${ }^{7}$ in order to evaluate the prevalence of aCL and antiphospholipid syndrome. All patients were treated in the outpatient clinic or ward of the Department of Rheumatology, Juntendo Hospital between 1993 and 1998. Patients with PSReA were diagnosed as having an acute sterile arthritis that developed after or during tonsillitis. All patients with PSReA had high titres of antistreptokinase and antistreptolysin $\mathrm{O}$, and group A Streptococcus was isolated from a tonsillar swab in $7 / 13$ patients. Four of the patients underwent tonsillectomy. The patients were followed up in the outpatient clinic for a minimum of three years (mean (SD) 5.2 (2.0) years). The titres of aCL (IgG class) and $\beta_{2}$ GPI dependent aCL in the sera were determined by an enzyme linked immunosorbent assay (ELISA). Serum samples from 15 healthy subjects and seven patients with IE were also evaluated.

Raised titres of aCL were found in 8/13 patients with PSReA (mean (SD) 2.36 (1.59), cut off index is 1.0 ), and 6/7 patients with IE (2.07 (1.65)) (fig 1). However, $\beta_{2}$ GPI dependent aCL were not detected in all patients with PSReA and IE (data not shown). In all the four patients with PSReA who underwent tonsillectomy, raised aCL titres normalised within six months. The raised titres of the remaining four patients with PSReA also fell within two years. No sign of thrombosis was seen in any of the patients with raised aCL titres during the observation period.

The major lipid bacterial component is the phospholipids, moreover, cardiolipin is especially rich in Gram positive bacteria. ${ }^{8}$ A previous study has shown that the reactivity of IgG class antibody in sera from patients with systemic lupus erythematosus to cardiolipin is inhibited by other phospholipids, such as phosphatidylserine. However, this polyreactivity was not recognised in serum samples from patients with infectious diseases. ${ }^{9}$ In patients with PSReA, continuous

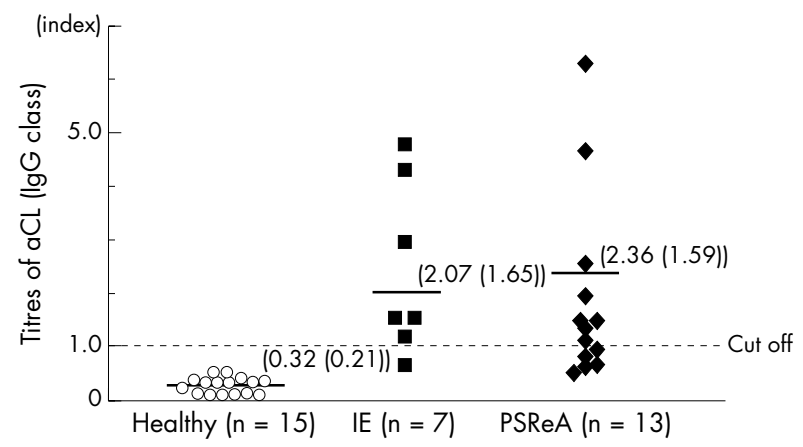

Figure 1 Raised titres of anticardiolipin antibodies $(\mathrm{aCl})$ in patients with post-streptococcal reactive arthritis (PSReA). The titres of lgG class aCL were determined by an ELISA in 15 healthy subjects, seven patients with infectious endocarditis (IE), and 13 with PSReA. The bar indicates the mean aCL titres of each group. The numbers indicate the mean (SD) titres of each group. The dotted line represents the cut off level (index 1.0).

survival of the bacteria, probably in a tonsillar microabscess, may result in transient production of aCL against bacterial cardiolipin. However, our observation suggests that aCL in PSReA are unlikely to lead to thrombotic events.

\section{Authors' affiliations}

N Tamura, S Kobayashi, H Hashimoto, Department of Rheumatology, Juntendo University School of Medicine, Tokyo, Japan

Correspondence to: Dr N Tamura, Department of Rheumatology, Juntendo University School of Medicine, 2-1-1, Hongo, Bunkyo-Ku, Tokyo, 113-8421,Japan; tnaoto@med.juntendo.ac.jp

Accepted 20 September 2001

\section{REFERENCES}

1 Cunningham MW, Hall NK, Krisher KK, Spanier AM. A study of anti-group $A$ streptococcal monoclonal antibodies cross reactive with myosin. J Immunol 1986;136:293-9.

2 Kraus W, Beachey EH. Renal autoimmune epitope of group A streptococci specified by $M$ protein tetrapeptide Ile-Arg-Leu-Arg. Proc Natl Acad Sci USA 1988;85:4516-20.

3 Aho K, Leirisalo-Repo M, Repo H. Reactive arthritis. Clin Rheum Dis $1985 ; 11: 25-40$

4 Kobayashi S, Tamura N, Akimoto T, Ichikawa G, Xi G, Takasaki Y, et al. Reactive arthritis induced by tonsillitis. Acta Otolaryngol 1996;(suppl 523):206-1 1

5 Delighton C. $\beta$ Haemolytic streptococci and reactive arthritis in adults. Ann Rheum Dis 1993;52:475-82.

6 Figueroa F, Berríos X, Gutiérrez M, Carrión F, Goycolea JP, Riedel I, et al. Anticardiolipin antibodies in acute rheumatic fever. J Rheumatol 1992; 19:1175-80.

7 McNeil HP, Simpson RJ, Chesterman CN, Krilis SA. Antiphospholipid antibodies are direct against a complex antigen that includes a lipid-binding inhibitor of coagulation: $\beta 2$-glycoprotein I (apolipoprotein H). Proc Natl Acad Sci USA 1990;87:4120-4.

8 Kates M. Bacterial lipids. Adv Lipids Res 1964;2:17-90.

9 Vaarala $\mathbf{O}$. Binding profiles of anticardiolipin antibodies in sera from patients with SLE and infectious diseases. J Autoimmun 1991;4:819-30 


\title{
Successful treatment of SAPHO syndrome with infliximab: report of two cases
}

\author{
I Olivieri, A Padula, G Ciancio, C Salvarani, L Niccoli, F Cantini
}

Ann Rheum Dis 2002;61:375-376

$\mathrm{T}$ he treatment of SAPHO syndrome is empirical and has recently been reviewed..$^{1-3}$ Non-steroidal antiinflammatory drugs (NSAIDs) are the first choice but have limited efficacy. Second line drugs have been tried with mixed results. Positive effects with pamidronate, which partly works by blocking tumour necrosis factor $\alpha$, have been reported. ${ }^{34}$ Recently, Maksymowych et al suggested that pamidronate is also effective in spondarthritis, which shares manifestations and clinical associations with the SAPHO syndrome. ${ }^{5}{ }^{6}$ Infliximab, a chimeric anti-tumour necrosis factor $\alpha$ monoclonal IgGl antibody, has recently been proved to be effective in the treatment of ankylosing spondylitis ${ }^{78}$ and psoriatic arthritis. $^{79}$

\section{CASE REPORTS}

In view of this information we treated two patients affected by refractory SAPHO syndrome with infliximab. Both patients had chest pain limiting normal activity despite adequate treatment with NSAIDs and second line treatment was unsuccessful. Both patients received three intravenous infusions of infliximab $(5 \mathrm{mg} / \mathrm{kg})$ at weeks 0,2 , and 6 and were evaluated at baseline, on days 3, 7, and 14, and then every two weeks.

\section{Patient 1}

The first patient was a 35 year old man who had had severe acne and painful osteitis of the left clavicle for 17 years. His family history showed that his mother had psoriasis and his brother had had one episode of acute anterior uveitis. Locus B HLA typing of the patient disclosed the B18 antigen. His disease had been treated with NSAIDs for 12 years. In 1996 he was given cyclosporin at a dose of $3 \mathrm{mg} / \mathrm{kg} / \mathrm{day}$, with some benefits for the chest pain only. The drug was stopped after two years owing to a loss of efficacy. In the following months long term antibiotic treatment with azithromycin, which has been suggested to be efficacious in SAPHO syndrome, ${ }^{10}$ was tried without any results.

When we decided to start infliximab treatment the patient had had severe pain of his left clavicle for three months despite treatment with nimesulide, the best alternative NSAID for our patient, at a dose of $400 \mathrm{mg} /$ day. The left clavicle was swollen, warm, and tender and florid acne was present on his face and posterior chest wall. Laboratory evaluation was normal except for a C reactive protein (CRP) of $13.5 \mathrm{mg} / \mathrm{l}$ (normal $<5)$. Three days after the first infusion the chest wall pain disappeared and the patient was able to stop NSAID treatment. Swelling and tenderness on the left clavicle remitted and the CRP returned to normal. Severe acne dramatically improved in one week. Chest wall pain, swelling and tenderness, and acne reappeared two months after the third infusion when we decided to proceed with a fourth infusion. The CRP was normal. Again a complete remission of the symptoms was seen in three days. The disease has remained in remission so far, two and a half months after the fourth infusion. Infliximab treatment was well tolerated, with no side effects.

\section{Patient 2}

The second patient was a 52 year old man with SAPHO syndrome affecting the sternum, the sternoclavicular joints, the clavicles, and the first two ribs. He had no family history of SAPHO syndrome or spondarthritis. Locus B HLA typing was positive for B35 and B52. His disease began at the age of 42 with palmoplantar pustolosis, which disappeared after six months. Five years later a severe chest wall pain appeared, which was treated with various NSAIDs for 10 years. In 1996 and 1997 he was given sulfasalazine, methotrexate, and cyclosporin A at different times, with no improvement. In the six months before the start of infliximab treatment the patient took $150 \mathrm{mg} /$ day diclofenac, with little result.

On the day on which the first infusion was given a physical examination showed tenderness and swelling on the manubrium sterni and both sternoclavicular joints. The only aspect of laboratory evaluation worthy of note was a CRP of $24 \mathrm{mg} / \mathrm{l}$ (normal $<5$ ). The day after the first infusion the chest wall pain disappeared and NSAIDs were discontinued. At the first visit, on day 3, a physical examination and CRP were normal. The disease remained in remission for two and a half months after the third infusion. Pain, swelling, and tenderness on the manubrium sterni and both sternoclavicular joints again disappeared in three days after the fourth infusion and have not reappeared so far, two months after the fourth infusion. No side effects of infliximab treatment were seen.

\section{COMMENT}

Our study suggests that infliximab is an effective drug in SAPHO syndrome. A larger, controlled, double blind study is required, which should also establish whether improvement of bone scan or magnetic resonance imaging parallels the clinical remission.

\section{ACKNOWLEDGEMENT}

Supported by the Government of Basilicata (Lucania) Region.

\section{Authors' affiliations}

I Olivieri, A Padula, G Ciancio, Rheumatology Department of Lucania, S Carlo Hospital of Potenza and Matera Hospital, Potenza and Matera, Italy

C Salvarani, Rheumatic Disease Unit, Arcispedale Santa Maria Nuova, Reggio Emilia, Italy

L Niccoli, F Cantini, Rheumatic Disease Unit, Prato Hospital, Prato, Italy

Correspondence to: Dr I Olivieri, Rheumatology Department of Lucania, San Carlo Hospital, Contrada Macchia Romana, 85100 Potenza, Italy; ignazioolivieri@tiscalinet.it

Accepted 25 October 2001

\section{REFERENCES}

1 Kahn MF, Khan MA. The SAPHO syndrome. Baillieres Clin Rheumatol 1994;8:333-62.

2 Hayem G, Bouchaud-Chabot A, Benali K, Roux S, Palazzo E Silbermann-Hoffman O, et al. SAPHO syndrome: a long term follow-up study of 120 cases. Semin Arthritis Rheum 1999;29:159-71.

3 Van Doornum S, Barraclough D, McColl G, Wicks I. SAPHO: rare or just not recognized? Semin Arthritis Rheum 2000;30:70-7.

4 Sayag-Boukris V, Laussadi S, Cormier C, Laroche F, Menkes CJ, Kahan A. Efficacy of pamidronate in the treatment of SAPHO syndrome [abstract]. Arthritis Rheum 1998;41(suppl):S114.

5 Maksymovych WP, Jhangri GS, Leclercq S, Skeith K, Yan A, Russel AS An open study of pamidronate in the treatment of refractory ankylosing spondylitis. J Rheumatol 1998;25:714-17. 
6 Maksymovych WP, Lambert R, Jhangri GS, Leclercq S, Chiu P, Wong B, et al. Clinical and radiological amelioration of refractory periphera spondyloarthritis by pulse intravenous pamidronate therapy. J Rheumato 2001;28:144-5

7 Van den Bosch F, Kruithof E, Baeten D, De Keyser F, Mielants H, Veys $E M$. Effects of a loading dose regimen of three infusions of chimeric monoclonal antibody to tumor necrosis factor $\alpha$ (infliximab) in spondyloarthropathy: an open pilot study. Ann Rheum Dis 2000;59:428-33.
8 Brandt J, Haibel H, Cornely D, Golder W, Gonzalez J, Redding J, et al. Successful treatment of active ankylosing spondylitis with anti-tumor necrosis factor alpha monoclonal antibody infliximab. Arthritis Rheum

9 Antoni C, Dechant C, Ogilvie A, Kalden-Nemeth D, Kalden JR, Manger B. Successful treatment of psoriatic arthritis with infliximab in a MRI controlled study. J Rheumatol 2000;27(suppl 59):24.

10 Wagner $A D$, Mai $U$, Hammer $M$, Zeidler $H$. Longterm antibiotic therapy successful in patients with SAPHO' syndrome [abstract]. Arthritis Rheum 1997:40 (suppl):S62

\title{
Muscle involvement in childhood sarcoidosis and need for muscle biopsy
}

\author{
A V Ramanan, A D Thimmarayappa, E M Baildam
}

$\mathrm{S}$ rcoidosis is a multisystem disorder with protean manifestations in childhood. ${ }^{1}$ We report on a child with prominent muscular symptoms at presentation. Muscle involvement in childhood sarcoidosis has been described in only two previous reports to our knowledge. ${ }^{23}$ We believe that muscle biopsy has a valuable role in aiding the diagnosis of childhood sarcoidosis even in children with no clinical symptoms of muscle involvement.

\section{CASE REPORT}

A 10.5 year old girl presented with a nine weeks' history of fever, red eyes, loss of appetite, malaise, florid widespread rash, weakness, and lymphadenopathy. She attended a district general hospital and was diagnosed to have a mycoplasma chest infection and treated with antibiotics. She failed to respond despite three courses of erythromycin and had persistent conjunctivitis, florid rash over her trunk, erythema nodosum over her legs, and weight loss and was therefore referred to our tertiary rheumatology unit.

On review, she was pale, miserable, tired with muscle wasting, weakness, and lymphadenopathy. A complete investigation was carried out and haematological tests showed haemoglobin $102 \mathrm{~g} / \mathrm{l}$ (normal 114-140 g/l) and white cell count 10.2 (normal 4-11). Her biochemical profile was normal and liver functions showed alanine aminotransferase 263 IU/l (normal 0-45 IU/l). Her autoantibody profile was negative, and inflammatory markers like $\mathrm{C}$ reactive protein $190 \mathrm{mg} / \mathrm{l}$ (normal <60 $\mathrm{mg} / \mathrm{l})$ and erythrocyte sedimentation rate $92 \mathrm{~mm} / \mathrm{lst} \mathrm{h}$ (normal $<5 \mathrm{~mm} / \mathrm{lst} \mathrm{h}$ ) were raised. Her lactate dehydrogenase $884 \mathrm{IU} / \mathrm{l}$ (normal $\leqslant 620 \mathrm{IU} / \mathrm{l})$, serum angiotensin converting enzyme $133 \mathrm{IU} / \mathrm{l}$ (normal 15-55 IU/1), and antistreptolysin O titre $>800$ (normal $<200$ ) were all raised. Her creatine kinase was normal. Her chest $x$ ray examination disclosed bilateral hilar lymphadenopathy with some pulmonary interstitial changes. An echocardiogram, cranial magnetic resonance imaging (MRI), magnetic resonance angiography, dimercaptosuccinic acid (DMSA) scan, and abdominal ultrasound were normal. Her muscle biopsy showed non-caseating, nonnecrotising granulomas in fibrous septa and within muscle fascicles. In areas there were granulomas surrounding muscle fibres, the latter showing degenerative features (fig l). The epitheloid granulomas had some admixed lymphocytes and giant cells. Skin biopsy showed granulomas in debris and subcutaneous tissues. A Mantoux test, gastric washings, and urine examination for acid fast bacilli were negative and bone marrow aspiration was normal. Ocular examination showed evidence of uveitis.

A diagnosis of sarcoidosis was made based on clinical and histological features and treatment was started with high dose

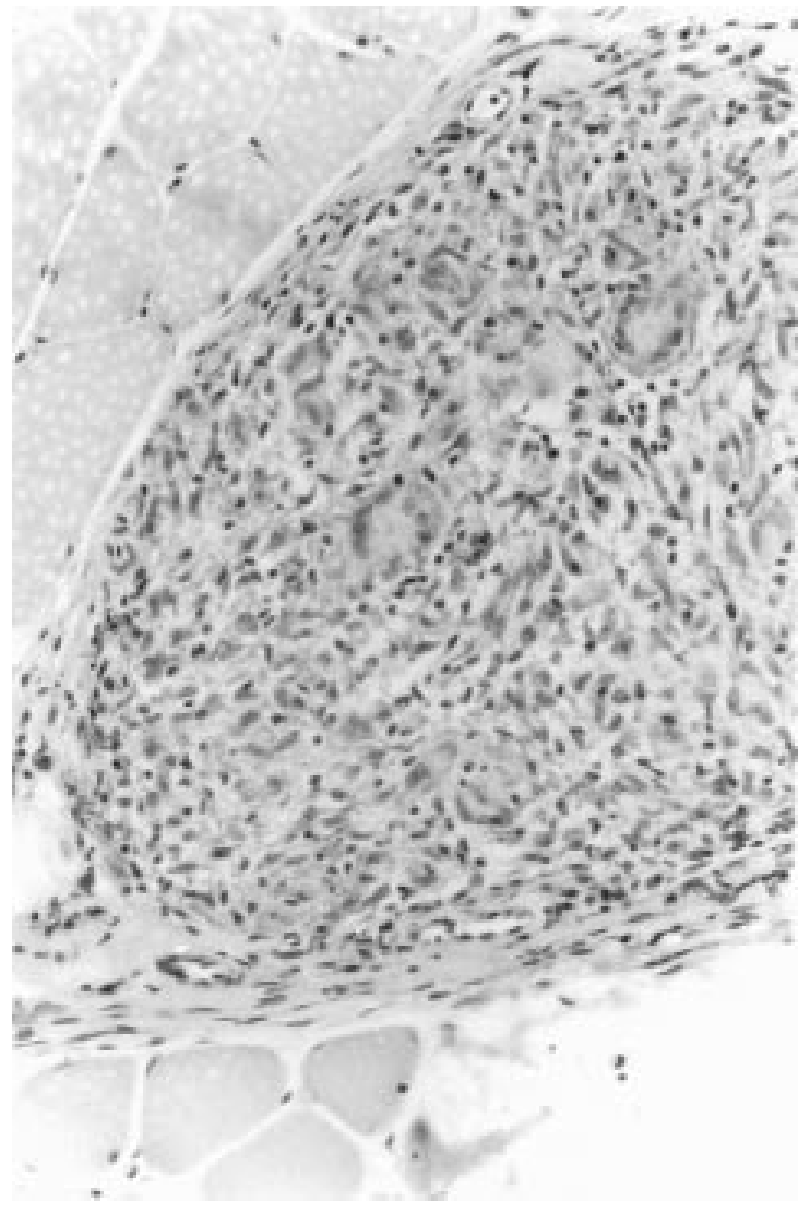

Figure 1 Muscle biopsy specimen showing well defined non-caseating granuloma. Magnification $\times 40$, haematoxylin and eosin

methylprednisolone at $30 \mathrm{mg} / \mathrm{kg} /$ dose, followed by oral prednisolone. During the course of illness, she developed a tender liver and raised transaminases suggestive of hepatic disease.

Currently she is in remission with no symptoms and has been weaned off steroids completely. No symptoms have recurred during the past three years of follow up. 


\section{DISCUSSION}

Childhood sarcoidosis is a chronic systemic disease of unknown cause, characterised by granuloma formation in affected organs. Childhood sarcoidosis is very rare, and the only incidence study done in children gives a figure of 0.22 $0.27 / 100000 .{ }^{4}$ Possibly, as in adults, a significant proportion of cases are asymptomatic and remain undiagnosed.

Muscle involvement in sarcoidosis is well recognised in adults. Symptomatic muscle involvement is reported to be between 0.5 and $1.4 \%$ of known cases of sarcoidosis. ${ }^{56}$ However, only two reports of muscle involvement in childhood sarcoidosis have been published. The clinical spectrum of muscle involvement in adult sarcoidosis can range from an asymptomatic state to a nodular myopathy (where lesions can be detected by MRI and gallium scintigraphy). ${ }^{7}$ Non-caseating granulomas have been detected in $20-75 \%$ of muscle biopsy specimens in adult patients with sarcoidosis, despite the absence of muscle symptoms. ${ }^{8-10}$

Our patient exhibited myopathic symptoms at presentation which improved with treatment. We believe that a diagnosis of sarcoidosis should be entertained in any child with unexplained muscle weakness and associated systemic symptoms.

We feel that muscle biopsy is useful in establishing the diagnosis of sarcoidosis and should be considered in children with sarcoidosis even if they have no muscle involvement (as sarcoid granulomas are seen in the skeletal muscle of $50 \%$ of adults with sarcoidosis with no muscle involvement).

\section{Authors' affiliations \\ A V Ramanan, A D Thimmarayappa, E M Baildam, Department of Paediatric Rheumatology, Royal Manchester Children's Hospital, \\ Charlestown Road, Manchester, UK}

Correspondence to: Dr A V Ramanan, Flat 508, 77 Elm Street, Toronto, Ontario M5G 1H4, Canada; avramanan@hotmail.com

Accepted 17 October 2001

\section{REFERENCES}

1 Shetty AK, Gedalia A. Sarcoidosis in Children. Curr Probl Pediatr 2000;30: 149-76

2 Celle ME, Veneselli E, Rossi GA, Lamba LD, Pessagno A, Ferriere G. Childhood sarcoidosis presenting with prevalent muscular symptoms. Eur J Pediatr 1997; 156:340-1.

3 Laniewar DN, Maheswari MB, Lakhani SN, Patel RB, Holla VV. Childhood sarcoid myopathy manifesting as joint contractures. Indian Pediatr 1996;33:128-30.

4 Milman N, Hoffman AL, Byg K-E. Sarcoidosis in children. Epidemiology in danes, clinical features, diagnosis, treatment and prognosis. Acta Paediatr 1998;87:871-8

5 Douglas AC, Macleod JG, Matthews JD. Symptomatic sarcoidosis of skeletal muscle. J Neurol Neurosurg Psychiatry 1973;36:1034-40.

6 Maycock RL, Bertrand P, Morrison CE, Scott JH. Manifestations of sarcoidosis: analysis of 145 patients, with a review of nine series sarcoidosis: analysis of 45 patients, with a review of nined from the literature. Am J Med 1963;35:67-89.

7 Otake S, Sarcoidosis involving skeletal muscle: imaging findings and relative value of imaging procedures. AJR 1994;162:369-75

8 Silverstien A, Siltzbach LE. Muscle involvement in sarcoidosis. Arch Neurol 1969;21:235-40.

9 Stjernberg N, Cajander S, Truedsson H, Uddendfeldt P. Muscle involvement in sarcoidosis. Acta Med Scand 1981;209:213-16.

10 Wallace SL, Lattes R, Malia JP, Ragan C. Muscle involvement in Boeck's sarcoid. Ann Intern Med 1958;48:497-511.

\section{Fever of unknown origin with seronegative spondyloarthropathy: an atypical manifestation of Whipple's disease}

\section{Várvölgyi, T Bubán, S Szakáll, Z Hargitai, L Galuska, C Jeney, G Kakuk, J Gaál}

M any authors emphasise the diagnostic difficulties and point out the multifaceted nature of Whipple's disease. ${ }^{12}$ Joint symptoms are present in $90 \%$ of all cases and may precede other disease manifestations by decades. ${ }^{3}$ We report here a case with fever of unknown origin accompanied by seronegative spondyloarthropathy with no typical gastrointestinal symptoms and initially negative upper panendoscopy. To confirm the diagnosis, the bacterial $16 \mathrm{~S}$ ribosomal RNA sequence of Tropheryma whippelii was determined by polymerase chain reaction (PCR).

\section{CASE REPORT}

A 58 year old white man had a 12 year history of intermittent arthralgias and seronegative polyarthritis. In 1993, monolateral stage II sacroiliitis was disclosed with no definite cause. Low dose methylprednisolone treatment was started, but there was no clinical improvement. In 1998 the patient became febrile, lost $10 \mathrm{~kg}$ of weight but had no gastrointestinal symptoms. He underwent an extensive examination, including radiological examinations of the chest and paranasal sinuses, abdominal sonography, echocardiography, abdominal computed tomography, upper panendoscopy, bone marrow biopsies, whole body gallium-67 citrate scan, multiple blood, stool, and urine cultures, as well as serological investigations for known viruses and autoantibodies. Results of all these tests were normal or negative except for mild spleno- megaly, transitory otitis, and temporary antinuclear antibody positivity. Fever of unknown origin was diagnosed. The patient often took antibiotics.

He was referred to our department in October 1999. Physical examination showed limitation in the lumbar spine, bilateral swollen and tender wrists, right sided proximal interphalangeal synovitis of the hand, minimal synovial fluid in the right knee, and bilateral tenderness of Achilles tendons. Radiographic examination showed bilateral stage II sacroiliitis. Non-differentiated seronegative spondyloarthropathy was diagnosed, and meloxicam ( $15 \mathrm{mg} /$ day) and methotrexate $(7.5$ $\mathrm{mg} /$ week) were started.

In January 2000 the patient's fever $\left(39^{\circ} \mathrm{C}\right)$ reappeared, but no malignant, infective, or autoimmune cause of the disease was shown. The differential diagnosis included rheumatoid arthritis, rheumatic fever, connective tissue disorders, reactive arthritis, adult Still's disease, sarcoidosis, arthritis with haematological and solid malignancies, familial Mediterranean fever, arthropathy associated with HIV infection, histiocytosis, some fungal infections, other seronegative arthropathies, including inflammatory bowel disease with spondyloarthropathy. Laboratory examinations showed raised $\mathrm{C}$ reactive protein level $(160 \mathrm{mg} / \mathrm{l})$, increased erythrocyte sedimentation rate $(82 \mathrm{~mm} / \mathrm{lst} \mathrm{h})$, and mild iron deficiency anaemia (haemoglobin, $116 \mathrm{~g} / \mathrm{l}$ ). All other laboratory parameters, including serum albumin, calcium, bilirubin, and HLA-B27 


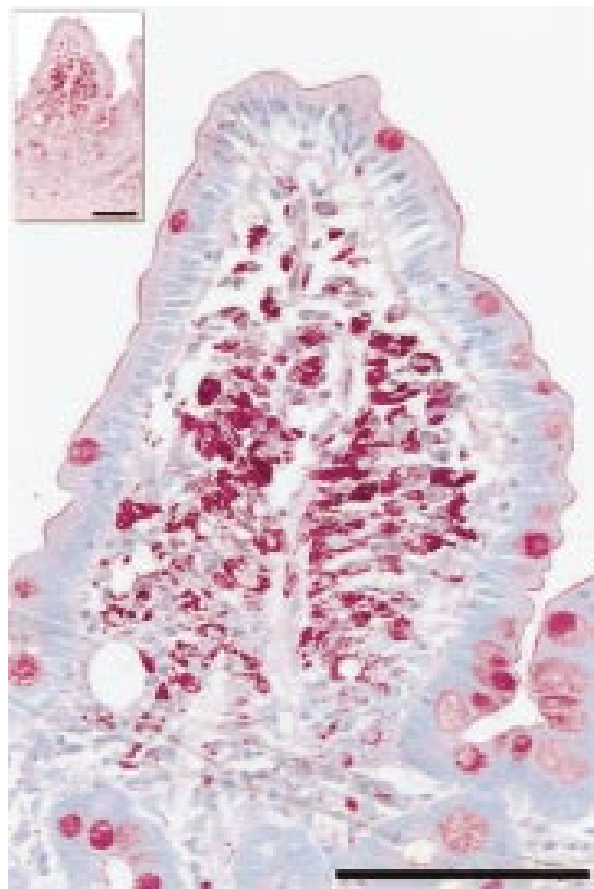

Figure 1 Biopsy specimen of the duodenal mucosa. The stroma is infiltrated with macrophages having a coarse granular intracytoplasmic PAS positivity. Bar represents $100 \mu \mathrm{m}$. Periodic acid-Schiff (PAS) stain.

antigen, were normal or negative. Colonoscopy did not show mucosal changes characteristic of inflammatory bowel disease. Upper gastrointestinal series with small bowel roentgenograms showed abnormal enteral peristalsis. A whole body ${ }^{67} \mathrm{Ga}$ citrate scan was performed again and showed increased accumulation in the small intestinal regions. Whipple's disease was suspected and repeated upper panendoscopy disclosed small whitish plaques in the duodenum. In the duodenal biopsy specimens, numerous periodic acid-Schiff (PAS) positive macrophages were seen (fig 1). PCR was unequivocally positive for bacterial $16 \mathrm{~S}$ rRNA from the formalin fixed and deparaffinated samples.

Meloxicam and methotrexate were continued with sulfamethoxazole-trimethoprim. From that time on the patient was free of fever and the arthralgia diminished markedly. Two months later the whitish plaques disappeared from the duodenum, but histological examination still detected macrophages with PAS positive inclusion bodies. PCR was intensely positive for bacterial 16S rRNA from the native samples.

The diagnosis of Whipple's disease is usually straightforward in cases with characteristic clinical manifestations. However, difficulties may arise when clinical features are atypical or the disease is oligosymptomatic. Despite the fact that dyspeptic symptoms were lacking, we repeated the upper panendoscopy in light of the patient's iron deficiency anaemia, weight loss, and questionable gallium scan report. Histological examination of duodenal mucosa showed PAS positive inclusions in macrophages in the lamina propria. In one series, endoscopic mucosal appearance was characteristic of Whipple's disease only in $72 \%$ of cases. ${ }^{4}$ In our patient, endoscopy was performed three times, but no report suggestive of Whipple's disease was recorded on the initial checkup.

\section{DISCUSSION}

The diagnosis of Whipple's disease generally relies on the histological detection of sickle form particle-containing cells stained red by the PAS reaction. However, the mucosal histological features are not always pathognomonic. Because some other PAS positive cells (for example, macrophage infiltrates in Mycobacterium avium or Rhodococcus equi infection of patients with advanced HIV infection) may mimic sickle form particle-containing cells of Whipple's disease, confirmation of the diagnosis is recommended. ${ }^{3}$ Electron microscopy is generally accepted as an accurate diagnostic tool for detecting $T$ whippelii, but it is expensive, time consuming, and needs special handing of biopsy samples. ${ }^{5}$ Recently, the organism has been characterised by amplification of its unique 1321 base sequence of the 16S rRNA (rRNA, small subunit) gene from tissue infected with $T$ whippelii. ${ }^{6}$ It offers a suitable alternative for diagnosing Whipple's disease in cases with atypical clinical features or when the histological diagnosis requires confirmation. ${ }^{35}$ PCR provides an important aid to histological examination of extraintestinal manifestations unaccompanied by gastrointestinal symptoms. ${ }^{2}$ PCR results did correlate with therapeutic results, but correlation between histology after treatment and clinical outcome has not been established. $^{7}$

In conclusion, Whipple's disease should also be considered in clinical syndromes of fever of unknown origin and seronegative spondyloarthropathy, even in those patients who do not develop gastrointestinal symptoms. PCR is a useful diagnostic tool and provides definite diagnosis of this rare but treatable disease

\section{Authors' affiliations}

C Várvölgyi, T Bubán, G Kakuk, J Gaál, Ist Department of Internal Medicine, University of Debrecen, Medical and Health Science Centre, Debrecen, Hungary

S Szakáll, Z Hargitai, Institute of Pathology, University of Debrecen L Galuska, Department of Nuclear Medicine, University of Debrecen C Jeney, H-MED Laboratory, Central Military Hospital, Budapest, Hungary

Correspondence to: Dr J Gaál, Ist Department of Internal Medicine, University of Debrecen, Medical and Health Science Centre, Debrecen 4012 Hungary, POB 19; gaali@ibel.dote.hu

Acepted 8 October 2001

\section{REFERENCES}

1 Knight SM, Symmons DPM. A man with intermittent fever and arthralgia. Ann Rheum Dis 1998:57:711-14.

2 Gubler JGH, Kuster $M$, Dutly F, Bannwart F, Krause M, Vögelin HP, et al. Whipple endocarditis without overt gastrointestinal disease: report of four cases. Ann Intern Med 1999;131:112-16

3 Dobbins WO III. The diagnosis of Whipple's disease. N Engl J Med 1995;332:390-2.

4 von Herbay A, Maiwald M, Ditton HJ, Otto HF. Histology of intestinal Whipple's disease revisited. Virchows Arch 1996;429:335-43.

5 von Herbay A, Ditton HJ, Mainwald M. Diagnostic application of a polymerase chain reaction assay for the Whipple's disease bacterium to intestinal biopsies. Gastroenterology 1996;1 10:1735-43.

6 Relman DA, Schmidt TM, MacDermott RP, Falkow S. Identification of the Relman DA, Schmidt TM, MacDermott RP, Falkow S. Id
uncultured bacillus of Whipple's disease. N Engl J Med uncultured bacillus of

7 Ramzan NN, Loftus E Jr, Burgart LJ, Rooney M, Batts KP, Wiesner RH, ef al. Diagnosis and monitoring of Whipple disease by polymerase chain reaction. Ann Intern Med 1997;126:520-7. 


\title{
Synovial fluid neutrophil function in RA: the effect of pregnancy associated proteins
}

\author{
C Belcher, M Doherty, S P M Crouch
}

Ann Rheum Dis 2002;61:379-380

$\mathrm{P}$ regnancy has been associated with remission of symptoms in $75 \%$ of women with rheumatoid arthritis (RA). ${ }^{12}$ This may in part be caused by depression of polymorphonuclear neutrophil (PMN) function, which reduces the degree of synovial fluid (SF) inflammation. This study compared the function of SF and peripheral blood neutrophils from patients with RA and normal subjects, and examined the in vitro effects of pregnancy associated proteins on neutrophil function.

Paired SF and blood samples were obtained from 15 patients with RA ( six male, nine female); peripheral blood was obtained from nine normal controls (three male, six female). All patients fulfilled American College of Rheumatology (ACR) criteria for RA. ${ }^{3}$ Patients with RA had a mean age of 63 (range 36-81); controls had a mean age of 35 (25-49). Patients with RA had mean disease duration of nine years (1-30); ESR levels mean $50 \mathrm{~mm} / \mathrm{lst} \mathrm{h}$ (SE 6.4) and CRP levels mean 59 $\mathrm{mg} / \mathrm{l}$ (SE 12.5). In this study, each patient acted as their own control, as both blood PMN and SF PMN were studied. This allowed inclusion of men, and women past child bearing age. All patients with RA were receiving disease modifying drugs; recruitment of subjects not taking drugs is virtually impossible, so this is a caveat in all studies of PMN function studies in RA.

SF samples were pretreated with hyaluronidase (Streptomyces hyalurolyticus). PMN were isolated as previously described. ${ }^{4}$ Superoxide anion production (respiratory burst activity) was determined by lucigenin and luminol enhanced chemiluminescence. ${ }^{5}$ Respiratory burst occurs when stimulated PMN convert molecular oxygen to toxic oxygen radicals through activation of NADPH-oxidase. This was measured in response to the physiological receptor agonist n-formylmethionyl-leucyl-phenyalanine (fMLP) and the diacylglycerol analogue phorbol myristate acetate (PMA). We found it was possible to stimulate SF PMN as well as RA blood PMN to initiate a respiratory burst, with greater superoxide anion production than normal blood PMN. SF PMN tended to show greater respiratory burst activity at low agonist concentrations (suggesting priming), although this did not reach statistical significance.

In the joint space PMN undergo degranulation and release their granule contents. Primary and secondary degranulation is demonstrated by increased expression of the integrin CD1lb and loss of L-selectin (CD62L). ${ }^{2}$ CD1lb, CD18, and L-selectin expression were determined by flow cytometry using a direct immunofluorescence method. ${ }^{6}$ RA blood PMN and SF PMN both showed a rise in CDIlb expression, but not CD18 expression. This indicates that SF PMN have undergone a degree of both primary and secondary degranulation and that was greater than the degranulation in RA blood PMN. SF PMN lost more L-selectin than RA blood PMN; but neither was significantly different from normal blood PMN. Using fMLP increases CD18 and CD11b expression in normal blood PMN and RA blood PMN, but not SF PMN. SF PMN appear to show maximal CDl l b expression without added stimulus and the addition of fMLP did not lead to increased loss of L-selectin. Figure 1 shows these results.
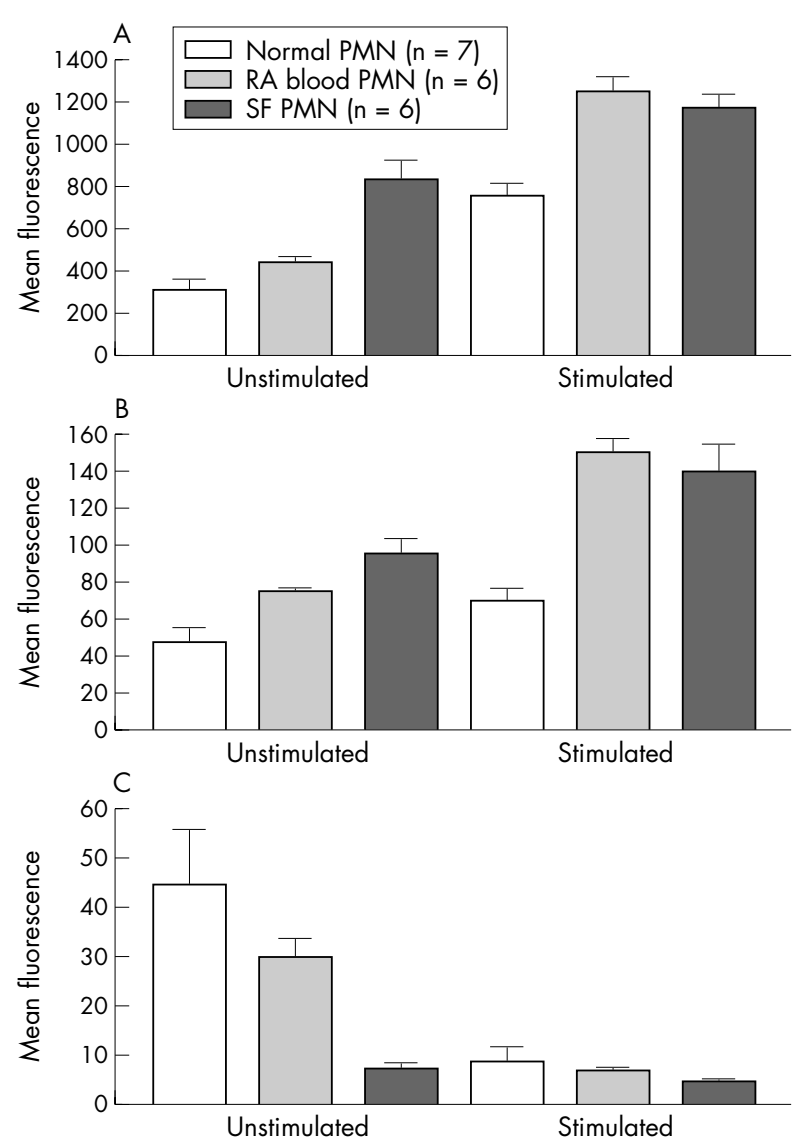

Figure 1 A comparison of adhesion molecule expression for normal blood, RA blood and synovial fluid for (A) CD $11 \mathrm{~b}$ expression, (B) CD 18 expression, and (C) CD62L expression. Values are represented as means (standard error).

The effect of pregnancy associated proteins was investigated by adding $10 \mathrm{~g} / \mathrm{ml} \beta$-oestradiol; $50 \mathrm{ng} / \mathrm{ml} \alpha$ fetoprotein; 10 $\mu \mathrm{g} / \mathrm{ml} \alpha_{2}$ macroglobulin; $50 \mathrm{U} / \mathrm{ml}$ human chorionic gonadotrophin (hCG)

SF PMN showed reduced extracellular superoxide production on incubation with hCG, and when stimulated with fMLP but not with PMA, suggesting a receptor mediated pathway of activation. This inhibitory effect was not observed in RA blood PMN. Production of SF PMN intracellular superoxide was inhibited by $\alpha$ fetoprotein in stimulated and unstimulated conditions; by $\alpha_{2}$ macroglobulin in stimulated conditions; and by $\beta$-oestradiol in unstimulated and fMLP stimulated conditions. These proteins may be exerting inhibitory effects on the myeloperoxidase dependent part of the respiratory burst pathway. This confirms a previous observation which highlighted the inhibitory effect of $\beta$-oestradiol on PMN superoxide production. ${ }^{7}$ Figure 2 shows these effects. 


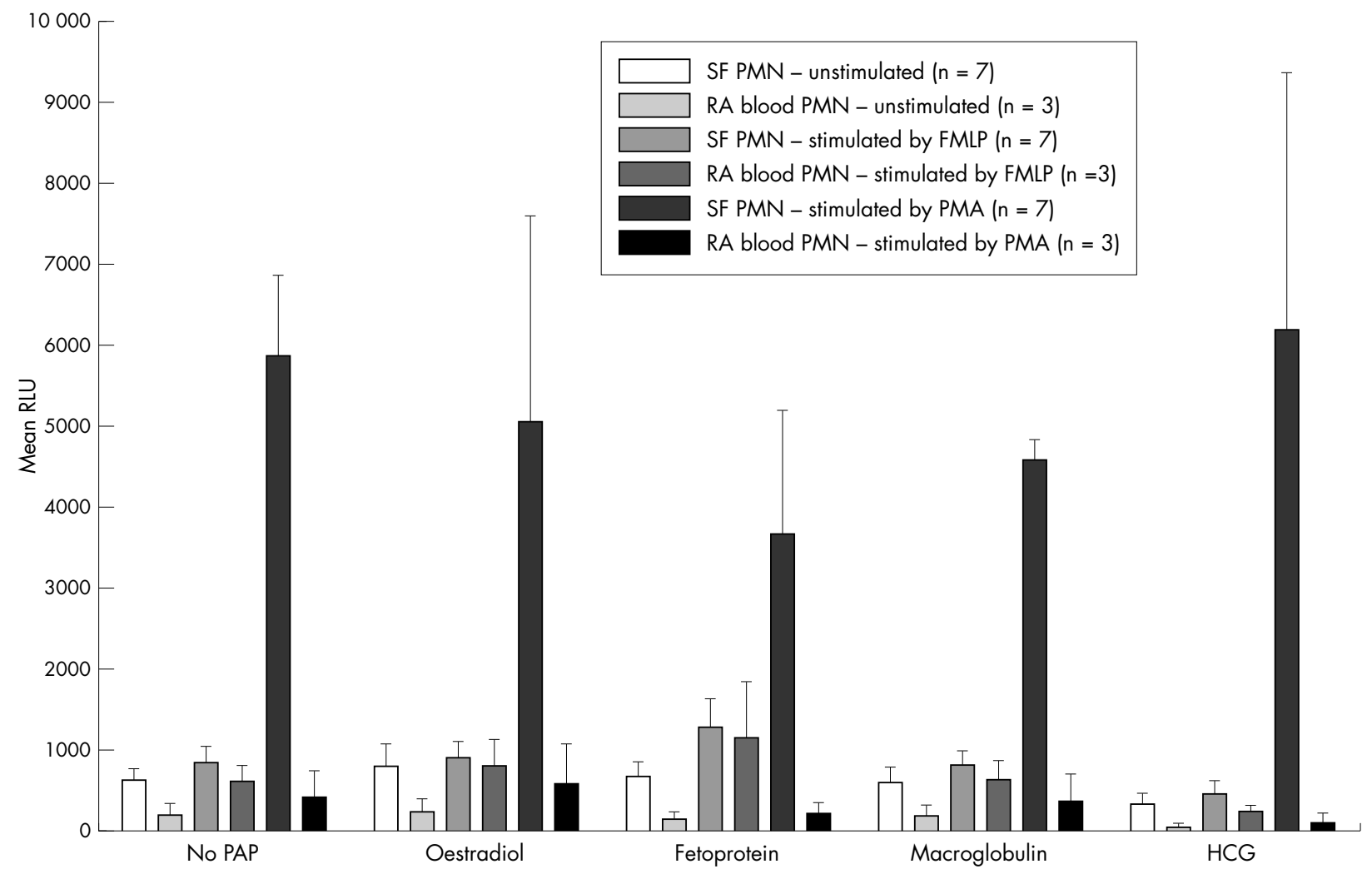

Figure 2 A comparison of the effects of pregnancy associated proteins on lucigenin enhanced chemiluminescence on unstimulated and stimulated SF and RA blood. Pregnancy associated proteins are $\beta$-oestradiol, $\alpha$ fetoprotein, $\alpha_{2}$ macroglobulin, and hCG. Values are represented as means (standard error).

In summary, we have shown that SF PMN are more responsive than peripheral blood PMN in RA. It would therefore be logical to target the reduction of activation and priming of these cells as a therapeutic approach to reduce inflammation in RA.

\section{ACKNOWLEDGEMENT}

This work was supported by the Arthritis Research Campaign.

\section{Authors' affiliations}

C Belcher, M Doherty, Academic Rheumatology, Clinical Sciences Building, City Hospital, Nottingham NG5 IPB, UK

S Crouch, David Evans Medical Research Centre, City Hospital, Nottingham

Correspondence to: C Belcher, Academic Rheumatology, Clinical Sciences Building, City Hospital, Hucknall Road, Nottingham NG5 1PB, UK; Carolyn.Belcher@Nottingham.ac.uk

Accepted 7 September 2001

\section{REFERENCES}

1 Persellin R H. The effect of pregnancy on rheumatoid arthritis. Bull Rheum Dis 1977;27:922-7.

2 Oka M, Vanio U. Effect of pregnancy on the prognosis and serology of rheumatoid arthritis. Acta Rheum Scand 1966;12:47-52.

3 Arnett FC, Edworthy SM, Bloch DA McShane DJ, Fries JF, Cooper NS, et al. The American Rheumatism Association 1987 revised criteria for the classification of rheumatoid arthritis. Arthritis Rheum 1988;31:315-24.

4 Watson F, Robinson JJ, Phelan M, Bucknall RC, Edwards SW. Receptor expression in synovial fluid neutrophils from patients with rheumatoid arthritis. Ann Rheum Dis 1993;52:354-9.

5 Crouch SPM, Fletcher J. The effect of ingested pentoxifylline on neutrophil superoxide anion production. Infect Immun 1992;60:4504-9.

6 Crouch SPM, Saihan SPM, Fletcher J. Effect of ingested pentoxifylline on the ex vivo function of patients with varicose leg ulcers. Clin Hemorheol 1994; 14:379-92.

7 Buyon JP, Korchak HM, Rutherford LE, Ganguly M, Weissmann G. Female hormones reduce neutrophil responsiveness in vitro. Arthritis Rheum 1984;27:623-30. 